\title{
Survey on indigestible foreign bodies in the rumen and reticulum of cattle slaughtered at Nekemte mu- nicipal abattoir, Nekemte, Ethiopia
}

\author{
Desalegn Jebessa ${ }^{1}$, Fethu Lemma*1, Tadelle Kabeta ${ }^{2}$, Birhanu Sibhat ${ }^{1}$ and Yitagele \\ Terefe ${ }^{1}$ \\ ${ }^{1}$ Haramaya University College of Veterinary Medicine, P.O. Box 138, Dire Dawa, Ethiopia. \\ ${ }^{2}$ Wollega University, School of Veterinary Medicine, P.O. Box: 395, Nekemte, Ethiopia. \\ *Corresponding author E-mail: fethu1431@gmail.com
}

\begin{abstract}
A cross sectional study was conducted on cattle slaughtered at Nekemte $\mathrm{Mu}$ nicipal Abattoir, Nekemte, East Wollega, Ethiopia from November 2015 to April 2016. The objectives of this study were to estimate the prevalence and to identify the type of indigestible foreign bodies in the rumen and reticulum of slaughtered cattle in association with the hypothetical risk factors. Each compartments of stomach was opened carefully and thorough visual inspection was made for the presence of indigestible foreign bodies. Of the 384 randomly selected cattle, overall foreign body detection was recorded in rumen and reticulum of $67(17.5 \%)$ the cattle examined. There was a higher prevalence of rumen and reticulum foreign bodies in female $(25.4 \%)$ than in male cattle $(15.4 \%)$ $(\mathrm{x} 2=3.99, \mathrm{p}<0.05)$. From the three age groups examined, the prevalence was higher (23.4\%) in animals in the old age group than the younger $(20.4 \%)$ and adult groups $(12 \%)\left(\mathrm{x}^{2}=7.9096 ; p<0.05\right)$. Foreign bodies collected were of different types including plastic (31.34\%), clothes (21.4\%), calcified bodies (4.5\%) and wires (4.5\%). Foreign bodies weighing $\geq 300$ grams were recorded in greater percentage $21(21.8 \%)$ in animals with poor body condition than those with medium 17(8.3\%) and good 6(7\%) body condition. This study revealed ingestion of different types of indigestible foreign bodies by cattle in the study area posing serious health problem for free grazing cattle. Hence, designing and implementation of appropriate solid waste disposal and management practice is strongly recommended to reduce the risk of ingestion of indigestible foreign bodies by cattle.
\end{abstract}

Keywords: Abattoir; Cattle; Foreign body; Nekemte; Reticulum; Rumen 


\section{Introduction}

The occurrence of foreign bodies in the rumen and reticulum of cattle is commonly seen in developing countries primarily due to indiscriminate feeding habits, improper waste disposal in the environment, nutritional deficiency and poor management system around home (Singh and Nigam, 1981). Industrialization and mechanization further increased the incidence of foreign bodies in animals in urban and semi urban areas (Misk, 1999). Cattle kept in farm yards, stables close to human mechanical activities are disposed to swallow metallic, plastic and non-plastic objects such as nails and pieces of wires that have been carelessly left in their feeding areas. They are exposed to indigestible materials resulting in high economic losses (Misk, 1984; Jones, 1997; Semieka, 2010; Tesfaye and Chanie, 2012). Most of these foreign bodies were found mainly in the fore-stomachs and they are responsible for most pathological conditions (Tehrani, 2012). This may lead to various complications including ruminitis, rumen impaction, traumatic pericarditis and traumatic reticulo-peritonitis, even penetrate pleural cavity causing pleuritis and pneumonia, and into the pericardial sac causing pericarditis (Hailat et al., 1996). It may ultimately lead to rumen distension, absence of defecation, reduced feed intake, failure of the absorption of volatile fatty acids, reduced rate of weight gain, internal injury, the perforation of the wall of the reticulum which allows leakage of ingesta and rumen microflora which contaminates the peritoneal cavity, resulting in inflammation of the peritoneum and consequently death (Abdullah et al., 1984; Igbokwe et al., 2003; Remi-Adewunmi et al., 2004).

In Ethiopia, the occurrence of rumen and reticulum indigestible foreign bodies in cattle had been reported in different regions. Occurrence rate of $23 \%$, $13.2 \%, 8.6 \%, 14.8 \%, 43.4 \%, 18.3 \%$, and $35.7 \%$ were recorded by Tefaye et al (2012), Tefaye and Chanie (2012), Nugusu et al (2013), Berrie et al (2015), Negash et al(2015), Ushula and Nana(2017), Mekuanint et al(2017), respectively. However, there is no published data on rumen foreign body of cattle in Nekemte area. Therefore, the objective of this study was to estimate the prevalence, type of foreign bodies and associated risk factors for indigestible foreign bodies in rumen and reticulum of cattle in Nekemte town. 


\section{Materials and methods}

\section{Study area}

The study was conducted in Nekemte town which is located about $331 \mathrm{~km}$ west of Addis Ababa, the capital city of Ethiopia (Fig. 1). It has a latitude and longitude of $9^{\circ} 5^{\prime} \mathrm{N} 36^{\circ} 33^{\prime} \mathrm{E}$ and an elevation of 2123 meters above sea level. The mean temperature of the study area is between $33-35^{\circ} \mathrm{C}$ with more agricultural crops and people in the country (NMSA, 2013). The area receives long heavy rain season from June to September and short rain season from March to May and the minimum annual rainfall is approximately $1450 \mathrm{~mm}$ and the maximum annual rainfall is $2150 \mathrm{~mm}$ with the average rainfall of $1800 \mathrm{~mm}$. The major agricultural production seasonally harvested includes chickpea, wheat, teff, maize and other legume crops. The total livestock population of the zone is estimated to constitute 85,584 cattle, 14,702 sheep, 11,861 goats, 98,674 equine and 94,276 chickens (NDAO, 2013).
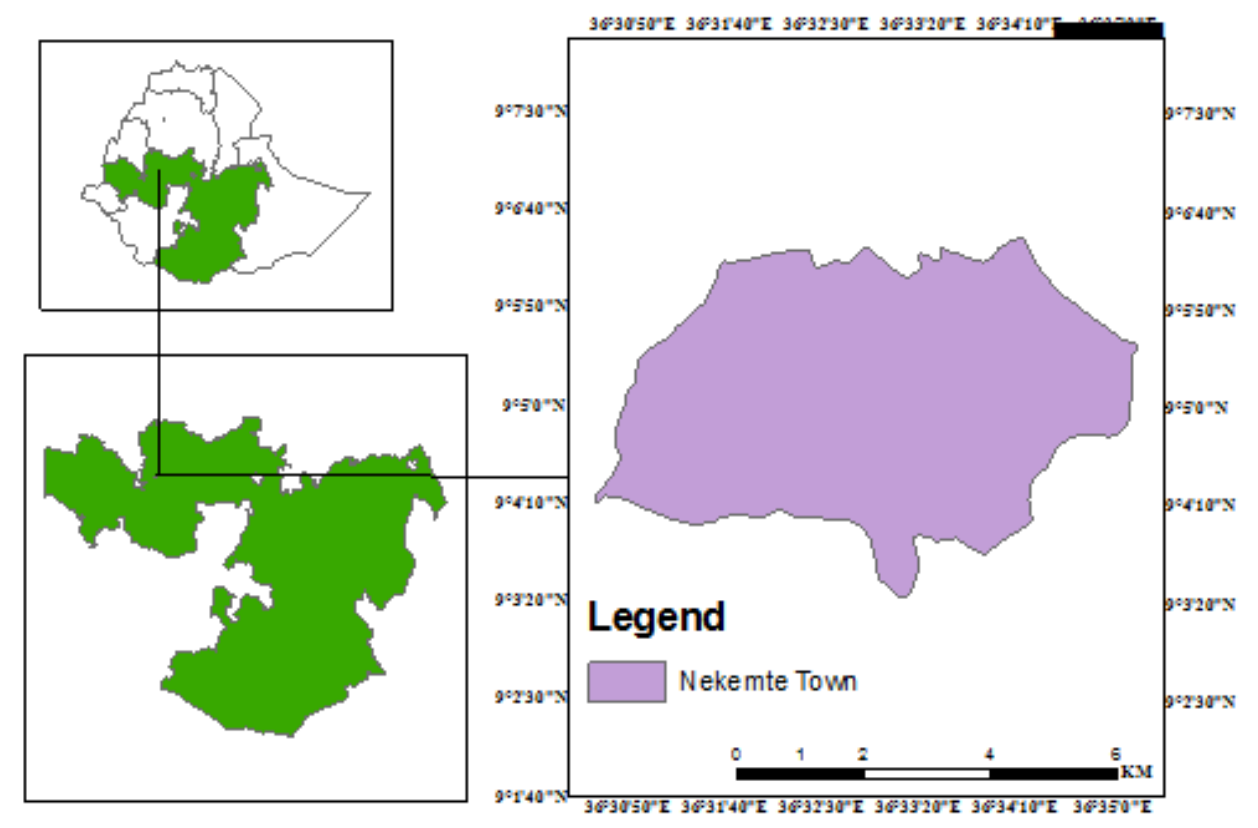

Figure 1. Map of study area (adapted from GIS desktop 10) 


\section{Study design}

A cross-sectional study was carried out from November, 2015 to April, 2016 at Nekemte municipal abattoir in the study area. The study was carried out on 384 cattle which originated from different agro-ecological zones and kept under different management system. The study animals originated from ArjoGudatu, Wayu-Tuka, Uke, Diga, Bandira and Amuma districts. Animals were selected from the study population by using simple random sampling technique. During sampling the sex, age, body condition, and origin of animals were recorded. Classification of the body condition of animal was made according to a method previously described by Nicholson and Butterworth, (1986) with scale ranging from poor, medium and good. The age of the animals was grouped as ( $\leq 5$ years), (5-10 years) and ( $\geq 10$ years).

\section{Sample size determination}

The required sample size was determined based on the procedure described by Thrusfield (2005); using 50\% expected prevalence of cattle foreign bodies in cattle in the area, and $5 \%$ desired absolute precision and at $95 \%$ confidence level. Accordingly, the total sample was determined to be 384 .

$$
n=\frac{\left(1.96^{2}\right) P_{\exp }\left(1-P_{\exp }\right)}{d^{2}}
$$

Where: $\mathrm{n}=$ required sample size, $\mathrm{P}_{\exp }=$ Expected prevalence and $\mathrm{d}=$ desired absolute precision. The sample size for this work was determined using $50 \%$ expected prevalence and $5 \%$ absolute precision at $95 \%$ confidence level using the above formula, the minimum of 384 cattle were intended to be sampled.

Ante mortem inspection: Animals presented for slaughter were subjected to ante-mortem inspection upon arrival at the abattoir. Ante-mortem inspection was conducted by applying a specific range of procedures that consider the behavior and appearance, as well as signs of disease in animals (FAO, 2009). Ante-mortem inspection of cattle took place in pens on the premises and each animal was observed at rest and in motion for the general status. Only animals that were judged to be sufficiently rested were proceeding to slaughter. Each animal selected for the study was further identified by providing a unique identification number that was used for the preceding postmortem examination. 
Postmortem examination: After slaughter and before flaying, slaughtered animals were identified by recording the code given at anti-mortem. Animals were visually inspected and their rumen and reticulum were palpated immediately post slaughter. Then, the stomach was gently removed from the abdominal cavity and all the contents were examined carefully for the presence or absence of any foreign material. The location and types of foreign bodies that were found in the stomach were properly recorded. When foreign bodies were found, they were removed, washed, and identified and photographed.

\section{Data analysis}

Data was entered into a Microsoft Excel spreadsheet and summarized using descriptive statistics. For analysis, SPSS Microsoft software Version 17.0 was used. Descriptive analysis and Pearson chi square $\left(x^{2}\right)$ test were employed to assess the existence of association between prevalence of the foreign bodies and different potential risk factors considered. P-values less than 0.05 was considered significant.

\section{Results}

\section{Overall prevalence of foreign body in rumen and reticulum of cattle}

From the total of 384 cattle examined for the presence of indigestible foreign bodies in their rumen and reticulum, 67(17.5\%) were found to be positive. From the $17.5 \%$ positive cases for rumen and reticulum foreign bodies, 40 (59.7\%) had foreign bodies in the rumen while 16 (23.8\%) in the reticulum and $11(16.4 \%)$ were positive for foreign bodies in both rumen and reticulum. The types of foreign bodies detected during this study were clothes, leather, rope, wire, plastic, calcified bodies, and the combination of both plastic and clothes and plastic and rope. These all comprise cloth 15(22.38\%), leather $6(8.9 \%)$, rope 7 (10.44\%), wire $3(4.47 \%)$, calcified body $3(4.47 \%)$, plastic $21(31.34 \%)$, plastic and cloth 8 (11.94\%) and plastic and rope 4 (5.97\%). Representative images of foreign bodies recovered from rumen and reticulum of cattle are shown (Figure 2). 

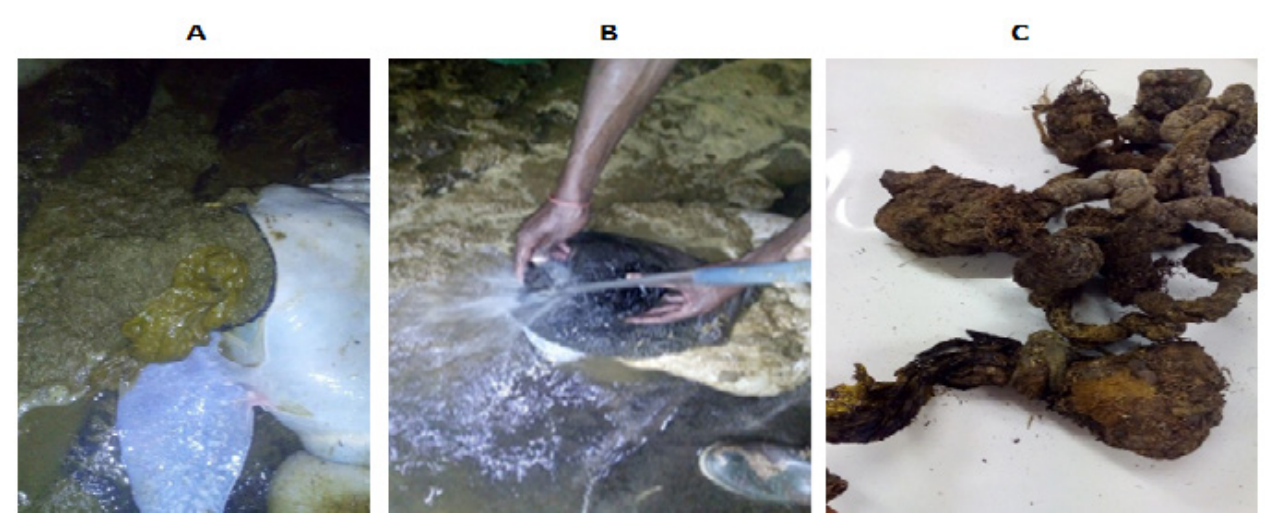

Figure 2. Representative image of indigestible foreign bodies from cattle slaughtered at Nekemte Municipal Abattoir A) Plastic bag recovered from rumen, B) A ball mass of leather, C) A rope and interwoven plastic bags.

\section{Prevalence of foreign body in relation to age}

Animals in this study were categorized into three age groups as ( $\leq 5$ years), (5-10 years) and ( $\geq 10$ years) consisting of 54,185 and 145 number of animals respectively. Eleven (20.4\%), 22(11.9\%) and 34(23.5\%) animals were positive for the presence of foreign bodies in rumen and reticulum in animals with age group of $\leq 5$ years, $5-10$ years, and $\geq 10$ years, respectively (Table 1 ). The prevalence of foreign body was significantly high in animals in the older age group compared to the other two groups $(p<0.05)$.

Table 1. Age distribution of rumen foreign bodies in cattle slaughtered at the Nekemte municipality abattoir

\begin{tabular}{lcccccc}
\hline Age group & $\begin{array}{l}\text { Number } \\
\text { examined }\end{array}$ & $\begin{array}{l}\text { Positive for } \\
\text { foreign body }\end{array}$ & $\begin{array}{l}\text { Prevalence } \\
(\%)\end{array}$ & $95 \%$ CI & $\mathrm{x}^{2}$ & $P$ value \\
\hline$\leq 5$ years & 54 & 11 & 20.4 & $10.6-33.5$ & 7.91 & 0.019 \\
5-10 years & 185 & 22 & 11.9 & $7.6-17.4$ & & \\
$\geq 10$ years & 145 & 34 & 23.5 & $16.8-31.2$ & & \\
Total & 384 & 67 & 17.5 & $13.7-21.6$ & & \\
\hline
\end{tabular}

\section{Weight of foreign bodies in relation to body condition score}

In this study, the result was divided in to two categories as those $\leq 300$ grams and $>300$ grams for simplicity. Among the total of 384 animals examined 23 
(6\%) animals contain foreign body weighing $\leq 300$ gm while $44(11.5 \%)$ animals contain foreign body weighing $>300 \mathrm{gm}$. Based on the body condition score $8(8.3 \%)$ and $21(21.8 \%)$ poor body condition animals had foreign bodies weighing $\leq 300 \mathrm{gm}$ and $>300 \mathrm{gm}$, respectively; while $14(6.8 \%)$ and $17(8.3 \%)$ animals with medium body condition had foreign bodies weighing $\leq 300$ and $>300 \mathrm{gm}$ respectively, and $1(1 \%)$ and $6(7 \%)$ animals with good body condition had foreign bodies weighting $\leq 300 \mathrm{gm}$ and $>300 \mathrm{gm}$ respectively (Table 2). Those animals in poor body condition had higher prevalence of foreign body weighing $>300$ gm followed by those with medium and good body condition score.

Table 2. Body condition score and weight of foreign body distributions in cattle slaughtered at the Nekemte municipality abattoir

\begin{tabular}{lllll}
\hline $\begin{array}{l}\text { Body } \\
\text { condition } \\
\text { score }\end{array}$ & Animals examined & $\begin{array}{l}\text { Animals with } \\
\text { foreign body }\end{array}$ & $\begin{array}{l}\text { Weight of foreign body } \\
\leq 300 \mathrm{gm}\end{array}$ & $>300 \mathrm{gm}$ \\
\hline Poor & 96 & 29 & $8(8.3 \%)$ & $21(21.9 \%)$ \\
Medium & 203 & 31 & $14(6.9 \%)$ & $17(8.4 \%)$ \\
Good & 85 & 7 & $1(1.2 \%)$ & $6(7.1 \%)$ \\
Total & 384 & 67 & $23(6 \%)$ & $44(11.5 \%)$ \\
\hline
\end{tabular}

\section{Prevalence of foreign body in relation to the origin of the animals}

Animals slaughtered at Nekemte municipal abattoir during this study came from six different districts (Amuma, Arjo-Gudatu, Bandira, Diga, Uke and Wayutuka). The highest prevalence was observed in cattle brought from ArjoGudatu whereas; there was no detection of foreign body from cattle originated from Amuma. In the present study significant association $(p<0.05)$ with the prevalence of the foreign bodies among locality was observed (Table 3 ).

\section{Prevalence of foreign bodies in relation to sex and body condition of cattle}

Among the total animals examined for the presence of foreign bodies 46, (17.6\%) male, and 21(25.4\%) female animals were positive for foreign body in their rumen and reticulum. This study showed that there was a significant difference in prevalence of foreign body between sex $(p=0.049)$. From the total of 96, 203 and 85 poor, medium and good scoring animals $29(30.2 \%), 31(15.2 \%)$ and $7(8.2 \%)$ were, respectively positive for foreign body in their rumen and re- 
ticulum. Statistically there was significant difference among the three groups of animals $(p<0.05)$ (Table 4$)$.

Table 3. Prevalence and frequency of foreign body distribution ofanimal originated from different localities and slaughtered at Nekemte municipality abattoir

\begin{tabular}{|c|c|c|c|c|c|c|}
\hline Origin & $\begin{array}{l}\text { Animals } \\
\text { examined }\end{array}$ & $\begin{array}{l}\text { positive } \\
\text { foreign } \\
\text { body }\end{array}$ & $\begin{array}{l}\text { Prevalence } \\
(\%)\end{array}$ & $95 \% \mathrm{CI}$ & $x^{2}$ & p-value \\
\hline Amuma & 9 & 0 & 0 & $0-33.6$ & 13.1 & 0.028 \\
\hline Arjogudatu & 78 & 20 & 25.6 & $16.4-36.7$ & & \\
\hline Bandira & 124 & 22 & 17.7 & $11.5-25.6$ & & \\
\hline Diga & 71 & 11 & 15.6 & 7.9-26.0 & & \\
\hline Uke & 81 & 11 & 11.6 & 6.9-23.0 & & \\
\hline Wayutuka & 21 & 3 & 14.3 & $3.0-36.3$ & & \\
\hline Total & 384 & 67 & 17.5 & $13.7-21.6$ & & \\
\hline
\end{tabular}

Table 4. Prevalence and frequency of rumen and reticulum foreign bodies in relation to sex and body condition score in cattle slaughtered in Nekemte abattoir

\begin{tabular}{llllllll}
\hline Factors & $\begin{array}{l}\text { Level of } \\
\text { factors }\end{array}$ & $\begin{array}{l}\text { Animals } \\
\text { examined }\end{array}$ & $\begin{array}{l}\text { Animals } \\
\text { with } \\
\text { foreign } \\
\text { body }\end{array}$ & $\begin{array}{l}\text { Prevalence } \\
\text { (\%) }\end{array}$ & 95\% CI & X $^{2}$ & $p$-value \\
\hline $\begin{array}{l}\text { Body } \\
\text { condition }\end{array}$ & Poor & 96 & 29 & 30.2 & $21.3-40.4$ & 16.5 & 0.001 \\
& Medium & 203 & 31 & 15.3 & $10.6-21.0$ & & \\
& Good & 85 & 7 & 8.23 & $3.4-16.2$ & & \\
Sex & Male & 299 & 46 & 15.4 & $11.5-20.0$ & 3.99 & 0.049 \\
& Female & 85 & 21 & 24.7 & $16-35.3$ & & \\
\hline
\end{tabular}

\section{Discussion}

Available literatures indicated that indigestible foreign body in rumen and reticulum is one of the most important diseases of cattle requiring surgical intervention in the third world countries. This study revealed an overall prevalence of $17.5 \%$ of rumen and reticulum indigestible foreign body in cattle slaughtered at Nekemte municipal abattoir. The result obtained from this preliminary work is in agreement with the reports of previous researchers (Bassa 
and Tesfaye, 2017; Ushula and Nana, 2017). Likewise, Mushonga et al (2015) obtained similar results from the rumen and reticulum of cattle in Rwanda. On the other hand, the result obtained from this study is higher than the report made by Tesfaye and Chanie (2012) from Jimma municipal abattoir and by Berrie et al (2015) from Gondar Elfora abattoir. On the contrary, reports made by Negash et al (2015) from Haramaya Municipal Abattoirs and Shiferaw and et al (2014) from the Amhara region showed a prevalence rate of $43.4 \%$ and $41.8 \%$, respectively. A higher prevalence rate was also reported by Mekuanint et al (2017) from Addis Ababa municipal abattoirs Khurshaid et al (2013) reported a prevalence rate of 59.14\% from Pakistan. Variations in the prevalence rate in the different regions seems to be due to the level of environmental pollution by plastic foreign materials as the use of plastic bags for carrying goods is less practiced in some of the localities. Grazing lands are contaminated with indigestible materials mainly by plastic foreign bodies in semi urban and urban areas. Hence those cattle raised in rural areas are less affected than those reared in semi urban and urban areas. Shortage of forage and absence of supplementary feed especially during the long dry season predispose the animals to a negative energy balance that in turn force them to eat unusual materials including plastics, cloth, rope and even metallic objects (Hailat et al, 1996; Tesfaye and Chanie, 2012).

The highest frequency of occurrence of rumen and reticulum foreign bodies were detected in animals greater than 10 years (23.45\%) followed by $5-10$ years $(11.83 \%)$ and less than 5 years $(20.4 \%)$. This finding is in agreement with Hailat et al (1998) who reported prevalence rate of $59.14 \%$ foreign bodies in rumen and reticulum in older cattle. Old dairy cattle are the most commonly affected group (Radostitis et al., 2007). Similarly, highest prevalence (81.25\%) of foreign bodies was detected in cattle greater than 10 year age by Khurshaid et al (2013). This finding was also in agreement with the work of Fromsa and Mohammed (2011) who recovered plastics, leather, clothes and ropes at higher prevalence from the rumen and reticulum of old sheep and goats. Mekuanint $e t$ al (2017) reported that indigestible rumen foreign body detection was higher in adult ruminants (46.7\%) than young ruminants (12.9\%). This might be associated with increase of exposure through life and many were found to accumulate and lead animals to be positive. The prevalence of foreign body was seen in female animals than male, there were a significant statistical difference $(\mathrm{x} 2=3.99 ; p=0.049)$ between sex were recorded. Tiruneh and Yesuwork (2010) reported higher degree of occurrence of foreign bodies in female sheep and goats compared to that of male. Similarly, Vanitha et al (2010) who detected 
foreign bodies more in female cattle than males in study on thirty (30) stray cattle having clinical symptoms suggestive of ruminal impaction. On the other hand, Mekuanint et al (2017) who reported detection of indigestible rumen foreign bodies in both sexes were not similar and there was not statistically significant difference between sexes. This result might associate with increased appetite of female animals due to the nutritional demands during difference in physiological status like during milking, prenatal period and lack of feed.

Regarding body condition score, the highest frequencies of occurrence of rumen and reticulum foreign bodies were detected in poor (30.2\%) followed by medium (15.3\%) and good (8.23\%) body conditioned cattle, and the difference were statistically significant $(p<0.05)$. This result was in agreement with the finding of Tesfaye and Chanie (2012) who reported $72.7 \%, 36 \%$ and $7.3 \%$ in poor, medium and good body condition score, respectively at Gondar Elfora abattoir. This study reveals higher frequency of foreign body occurrence in animals having poor body condition than in good body condition animals and which was also reported in other studies (Fromsa and Mohammed, 2011; Hailat et al., 1996; Tesfaye and Chanie, 2012). Accumulation of indigestible foreign bodies in the rumen interfere with the flow of ingesta and decrease absorption of volatile fatty acid and thus cause reduced weight gain (Igbokwe, 2003; RemiAdewunmi et al., 2004; Ismael et al., 2007). These effects contributed to poor body condition, and in long period of time, these materials form large tight balls inside the rumen leading to decreased production and loss of weight gain (Tyagi and Singh, 1993).

In this study, foreign bodies in rumen (10.4\%) and in reticulum (4.16\%) were recorded. This finding was in agreement with the findings of Bassa and Tesfaye (2017) who reported $10.83 \%$ in Wolaita Sodo municipal Abattoir. Similarly, Ushula and Nana (2017) also reported (87\%) occurred in the rumen and (13\%) occurred in reticulum at Hawassa municipal abattoir. This finding also agrees with the work of Tesfaye and Chanie, (2012) who reported the higher number of foreign bodies occurrence in the rumen $(79.2 \%)$ than in the reticulum (20.8\%). Furthermore, Khurshaid et al (2013) also reported that most foreign bodies were encountered in the rumen (58.45\%) than the reticulum (19.32\%) of Achai cattle at different regions in Pakistan. This is attributed to the larger rumen volume, the cumulative size and material composition of the foreign bodies, and the types of materials, with metals and sharp objects tending to localize preferentially in reticulum (Radostits, 2007). Plastic was 
the most commonly encountered (31.5\%) foreign material, followed by cloth (22.4\%) and the least encountered were calcified materials and wire both comprising (4.5\%) each. This finding in general agreed with various reports from different areas of Ethiopia (Fromsa and Mohammed 2011; Tiruneh and Yesuwork, 2010; Sheferaw et al., 2014; Tesfaye and Chanie, 2012). Igbokwe (2003), Remi- Adewunmi (2004) from Nigeria and Hailat (1996) from Jordan also reported similar findings. This showed that the wide spread use of plastic bags in these areas, improper disposal, and also lack of proper disposal of used and trimmed cloths elsewhere in the environment.

The highest prevalence of foreign body was observed in animals originated from Arjo-Gudatu (25.6\%) and the zero prevalencewas recorded in those originated from Amuma. According to Ismael et al (2007); Misk et al (1999); Singh and Nigam (1981), the difference in the prevalence rate in locality could be due to difference in the origin of animals and awareness of community about waste management system. Arjo-Gudatu is small town so that the animals have a chance to get access to pieces of metal and plastics around construction sites. Moreover, improper disposal of plastic bags from shops, market places, and by the public could have contributed for the higher occurrence of the problem in those animals originated from Arjo-Gudatu. Industrialization and mechanization of agriculture could be the other factor in the increased occurrence of foreign bodies in animals originated from this area. Lack of extensive free grazing area, forced the animals to look for feed, to go to nearby town, market place and road side that are polluted with those indigestible materials.

While comparing weight of foreign body versus body condition score of animals foreign bodies weighing $\geq 300$ grams were observed higher in poor body condition animals $(21.8 \%)$ than in medium $(8.4 \%)$ and good $(7.1 \%)$ body condition animals. A slight agreement is observed with work conducted in small ruminants in Addis Ababa municipal abattoirs (Tiruneh and Yesuwork, 2010). This shows poor body condition by itself might be due to the contribution of the higher weighing place occupied by foreign body that is the animal loss weight after it has been exposed or it might be due to the interference of foreign body with the absorption of volatile fatty acid and thus causes reduced weight gain. 


\section{Conclusion}

This study showed the presence of improper use and disposal of plastics bags, and improper disposal of materials made up of plastics and metals posing risk to the health of cattle grazing in the area. Shortage of feed also increases the likelihood of ingestion of foreign bodies. Therefore, as the country progress in industrialization and mechanization, the responsible body in government has accountabilities for creating awareness on the impact of foreign bodies on the health of animals. There should be environmental bio-remediation mechanism to minimize the risk of foreign body and examination of suspected animals using ultrasonography which may aid in early diagnosis of foreign bodies which are difficult to detect by clinical examination alone. Further study should be conducted to assess the production and economic effects of foreign body accumulation.

\section{Acknowledgements}

The authors are thankful to the technicians of Nekemte abattoir who assisted in sample collection during study period. Many thank also goes to Haramaya University, College of Veterinary Medicine for the scientific support throughout the study period.

\section{Conflict of interest}

The authors declare that there is no conflict of interest.

\section{References}

Abdullah, U.S., Usman, G.S.H. and Mshelia, T.A., 1984. Impaction of rumen with indigestible garbage in cattle and sheep reared within urban and sub-urban environment. Nigerian Vet. J.,13, 89-95.

Bassa, K. and Tesfaye,W., 2017. Study on rumen and reticulium foreign bodies in cattle slauthered at Wolaita Sodo municipal Abattoir, Ethoipia. Int. J. Adv. Multidiscip. Res., 4, 1, 11-19.

Berrie, K., Tadesse E., Mossie,B. and Anteneh, B.,2015.Study on Rumen and Reticulum Foreign Body in Slaughtered Cattle at Gondar Elfora Abattoir, World J. Biol. Med. Sci.,2,4, 133-150. 
Food Agricultural Organization (FAO), 2009. Good Practices for the Meat Industry. Food and Agriculture Organization of the United Nations, Rome, Italy.

Fromsa, A. and Mohammed N., 2011. Prevalence of indigestible foreign body ingestion in small ruminants slaughtered at Luna export abattoir, East Shoa. Ethiopia. $J$. Anim. Vet. Adv.,10, 12, 1598-1602.

Hailat, N., AI-Darraji, A., Lafi, S. and Barakat, S., 1998. Pathology of the rumen in goats caused by plastic foreign bodies in Jordan with reference to its prevalence and evidence of partial degradation. Small Rumin. Res.,30, 77-83.

Hailat, N., South, S., Darraji, A. and Majali, A., 1996. Prevalence and Pathology of foreign bodies (plastics) in Awassi sheep in Jordan. Small Rumin. Res., 24, 43-48.

Igbokwe, I., Rolo, M. and Egwu, G. 2003. Rumen impaction in sheep with indigestible foreign bodies in the semi-arid of Nigeria. Small Rumin. Res., 49,141-146.

Ismael, Z.B., Al-Majabi, A. and Al-Qudah, K. 2007.Clinical and surgical findings and outcome following rumenotomy in adult dairy cattle affected with recurrent rumen tympany associated with non-metallic foreign bodies. American J. Anim. Vet. Sci., 2, 66-70.

Jones, T.C., Hunt, R.D. and King, N.W., 1997, Veterinary Pathology, 6th edn, Lippincott, Williams and Wilkins; USA, Pp 1060-1061.

Khurshaid, A., Ikhwan, K., Asim, A., Muhammad, M., Anwarud, D., Yasir, A. and Zubair, A., 2013. Prevalence of indigestible rumen and reticulum foreign bodies in Achai cattle at different regions of Khyber Pakhtunkhwa. Asian Res. Pub. Network. 8,580-586.

Mekuanint, S., Tewodros A. and Tsegaye A., 2017. Indigestible Rumen Foreign Bodies - Causes of Rumen Impaction in Cattle, Sheep and Goats Slaughtered at Addis Ababa Abattoir Enterprise, Ethiopia. J. Vet. Sci. Med., 5, 1- 6.

Misk, N.A., Nigam, J.M. and Rifat, J.F., 1984. Management of foreign body syndrome in Iraqi cattle. Agri. Practi., 5(8), 19-21.

Mushonga, B., Habarugira, G., Musabyemungu, A., Udahemuka, J.C., Jaja, F.I. and Pepe, D., 2015. Investigations of foreign bodies in the fore-stomach of cattle at Ngoma Slaughterhouse, Rwanda. J. S. Afr. Vet. Assoc., 86(1), 1233. 
tympany associated with non-metallic foreign bodies. American J. Anim. Vet. Sci., 2, 66-70.

Jones, T.C., Hunt, R.D. and King, N.W., 1997, Veterinary Pathology, 6th edn, Lippincott, Williams and Wilkins; USA, Pp 1060-1061.

Khurshaid, A., Ikhwan, K., Asim, A., Muhammad, M., Anwarud, D., Yasir, A. and Zubair, A., 2013. Prevalence of indigestible rumen and reticulum foreign bodies in Achai cattle at different regions of Khyber Pakhtunkhwa. Asian Res. Pub.Network. 8,580-586.

Mekuanint, S., Tewodros A. and Tsegaye A., 2017. Indigestible Rumen Foreign Bodies - Causes of Rumen Impaction in Cattle, Sheep and Goats Slaughtered at Addis Ababa Abattoir Enterprise, Ethiopia. J. Vet. Sci. Med., 5, 1- 6.

Misk, N.A., Nigam, J.M. and Rifat, J.F., 1984. Management of foreign body syndrome in Iraqi cattle. Agri. Practi., 5(8), 19-21.

Mushonga, B., Habarugira, G., Musabyemungu, A., Udahemuka, J.C., Jaja, F.I. and Pepe , D., 2015. Investigations of foreign bodies in the fore-stomach of cattle at Ngoma Slaughterhouse, Rwanda. J. S. Afr. Vet. Assoc., 86(1), 1233.

Negash, S., Sibhat, B. and Shiferaw, D., 2015. A postmortem study on indigestible foreign bodies in the rumen and reticulum of ruminants, eastern Ethiopia, Onderstepoort J. Vet. Res., 82( 1), 881-886.

Nekemte District Agricultural Office (NDAO), 2013.Annual report on population size and agriculture of the district, Nekemte.

Nicholson, M.J. and Butterworth, M.H. 1986. A guide to scoring of zebu cattle, International Livestock Centre for Africa, Addis Ababa. Ethiopia. Pp.36.

NMSA (National Meteorological Services Agency), 2013. Monthly report on temperature and Rainfall Distribution for Eastern Wollega Zone, Regional Metrological Office, Nekemte, Ethiopia.

Nugusu, S., Ramaswamy, V., Chandrashekhar, U. and Raja, N., 2013. Studies on foreign body ingestion and their related Complications in ruminants associated with inappropriate Solid Waste Disposal in Gondar Town, North West Ethiopia. Int. J. Anim. Vet. Adv.,5(2), 67-74.

Radostitis, O., Gay, C. and Hinchcliff, K., 2007. Veterinary Medicine, A Text book of disease of cattle, sheep, pig, Horse and goat, 10th ed. Artesobrepapa Spain, Pp. 337.

Remi-Adewunmi, B., Gyang, E. and Osinow, R., 2004.Abattoir survey of foreign body rumen impaction in small ruminants. Nigerian Vet. J., 25, 32-38.

Semieka, M., 2010. Radiography of unusual foreign body in ruminants. Vet. World, 3, 473-475. 
Sheferaw, D., Gebru, F., Asrat, M., Tesfaye, D. and Debela, E., 2014, Ingestion of indigestible foreign materials by free grazing ruminants in Amhara Region, Ethiopia. Trop. Anim. Hlth. Prod., 46, 247-250.

Singh, A.P. and Nigam, J.M., 1981.Radiography of the foreign bodies in the bovine in India. Bovine Practi., 2(6), 7-13.

Tehrani, A., Javanbakht, J., Marjanmehr, S.H., Hassan, M.A., Solati A. and Dezfouli, A.B., 2012. A pathological lesions study of bovine abomasums in Urmia abattoir. J. Clin. Exp. Pathol., 2, 5, 121.

Tesfaye, D. and Chanie M., 2012. Study on Rumen and Reticulum Foreign Bodies in Cattle Slaughtered at Jimma Municipal Abattoir, South West Ethiopia. AmericanEurasian J. Sci. Res.,7,(4), 160-167.

Tesfaye, D., Daba, D., Mekibib, B. and Fekadu, A., 2012.The problem of environmental pollution as reflected in the fore stomach of cattle: A postmortem study in Eastern Ethiopia. Global J. Envi. Res., 6(2), 61-65.

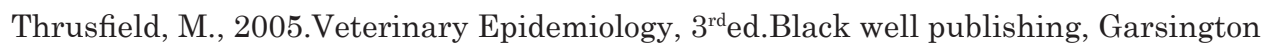
road, Oxford, UK. Pp. 233-250.

Tiruneh, R. and Yesuwork, H., 2010, Occurrence of rumen foreign bodies in sheep and goats slaughtered at the Addis Ababa Municipality Abattoir. Ethiop. Vet. J., 14(1), 91-100.

Tyagi, R. and Singh, J., 1993. Hernia ruminant's surgery, $1^{\text {st }}$ edn. New Delhi, India: CBS publishers and Distributors, Pp. 225-237.

Ushula, B.and Nana,T., 2017. Prevalence of rumen and reticulum foreign bodies in cattle slaughtered at Hawassa municipal abattoir, southern Ethiopia. World J. Pharm. Life Sci., 3(1), 521-534.

Vanitha, V., Nambi, AP., Gowri, B., and Kavitha, S., 2010. Rumen impaction in cattle with indigestible foreign bodies in Chennai Tamilnadu. J. Vet. Anim. Sci., 6, 138140 . 